\title{
Adaptive work program of physical education lessons for elementary school students with disabilities
}

\author{
Irina A. Kustova ${ }^{1}$, Anna $V$. Starostina ${ }^{1}$, Alexander $V$. Nikulin ${ }^{1}$, and Elena $V$. Sedunova ${ }^{1}$ \\ ${ }^{1}$ Department of Physical Education, Sports and Adaptive Physical Education, Vologda State \\ University, Russia
}

\begin{abstract}
At the stage of the implementation of inclusive education into the country's general education schools, many experts note that the teaching staff of schools is not ready to work with children with special educational needs. Lack of professional competencies affects the appearance of psychological barriers and professional stereotypes. Therefore, the purpose of the study was to develop an education program for physical education lessons for students with disabilities to increase their level of physical fitness. In the course of the study, the following methods were used: the method of literary source analysis, the method of examination, testing, pedagogical experiment, mathematical statistics. This article presents experimental material on the adaptive work program of physical education lessons for 1 st grade students with disabilities. It describes various methods and means of teaching this category of schoolchildren, develops guidelines for the sections of the subject "Physical Education" taking into account the age-related characteristics of schoolchildren with pathologies. The positive results of the study suggest the effectiveness of this adaptive educational program. The study is practically significant as it can be used to conduct lessons for children with disabilities in order to facilitate learning and eliminate health problems identified by health care workers.
\end{abstract}

\section{Introduction}

At the present stage of development of the Russian society, scientists note an increase in the number of children born with health disabilities. Specialized institutions are being opened for socialization of such children, thought after graduating from them, many children are faced with the problem of the lack of a tolerant attitude towards them in the society and the lack of special opportunities for their fulfilling life. Considering all this, in recent years, there has been a tendency to create open spaces for people with disabilities in all the spheres of society. The percentage of classes in general education schools with open inclusive and remedial education is increasing. Many schools participate in the Accessible Environment project, where a special logistical base for children with disabilities (sensory rooms) appears, which helps in the development and adaptation of children with disabilities. 
It is known that the Federal Law of the Russian Federation "On Education in the Russian Federation" in Art. 2 p. 27 consolidates the concept of "inclusive education" the meaning of which is "to ensure equal access to education for all students, taking into account the diversity of special educational needs and individual opportunities" [3].

The implementation of inclusive and remedial education in general education schools had a positive impact on children with disabilities, helping them socialize which they would sooner or later have to go through, and on healthy children as well. This is due to the fact that the child's psyche is more flexible and is able to adapt to the current situation, which gives us the result of a positive and warm attitude towards children with disabilities [13].

Due to the fact that this type of education in a modern school affects the deeper social components of school life it's a priority to create the essential learning environment, which includes moral, material and pedagogical aspects adapted to educational needs.

Based on the information in Russia and the world, we can indicate the urgency of the problem of mental health of children. Due to the increase in the number of mental and somatic as well as various functional disorders which correlates with a general decline in academic performance, especially at the initial stages of education, we can say that the modern world simply needs to change the approach to teaching.

According to psychological and pedagogical studies, the number of students who are not able to master the general education programs of primary school constitutes $20-30 \%$ of students, and approximately $70-80 \%$ of them need special forms and methods of teaching [15].

Due to the fact that there are reasons for the lower educational attainment, it is evidently necessary to improve the school education itself, especially at the stage of primary education, when the knowledge base for the cognitive ability of a child is laid, as well as the basic rules of discipline.

In particular defectologists have identified a specific category among underachieving schoolchildren, namely children with temporary mental retardation. It is this category that is in dire need of correctional work [7].

Having studied the academic literature data, we came to the conclusion that at the present stage of implementation of inclusive and corrective education in schools, there is a number of problems with education programs for classes with disabilities. This issue shows the emerging contradictions between the successful implementation of inclusive education in the country's general education schools and the unpreparedness of the teaching staff of schools to work with children with special educational needs.

Lack of professional competencies tends to emerge psychological barriers and professional stereotypes. The ability to find an approach to children, taking into account their individual characteristics can be noted as one of the main tasks of a general education school teacher. According to N.M. Nazarova, it is necessary to include the cooperation of teachers of mass and correctional schools as the most effective way to meet the special needs of children with disabilities in an inclusive class [8].

In our opinion, the most favorable testing ground for solving this problem is adaptive physical education at school, because for children with pathologies physical exercise is of great importance and is both an effective tool and a method of physical, psychological and social adaptation in the environment, and it is the most important means of increasing their physical preparedness [16].

Therefore, we consider it relevant to conduct a research in this direction.

The aim of the study was to increase the level of physical fitness of children with disabilities by developing a new program.

The objectives are:

1. To examine existing academic literature data on the research problem. 
2. By means of a questionnaire, to identify the subjective point of view of teachers in the issue of inclusive and remedial education.

3. To develop adapted education program for physical education lessons for children of 7-8 years old with disabilities.

4. During the pedagogical experiment to test the effectiveness of the developed work program.

The methods used in the course of our research are: the method of analysis and generalization of literary sources, the method of examination, testing, pedagogical experiment, mathematical statistics.

The practical significance of the study lies in the fact that its results can be used to conduct lessons and classes in order to facilitate the education of children with developmental disorder and eliminate the problems identified by medical workers through physical education.

Due to the technological progress, we can notice frequent innovative changes around us. Inclusive and remedial education in general education schools is a new round in the broader development of children, which can rightfully be called an innovation of the present.

Inclusive education according to A.A. Kolupaeva "provides for the creation of an educational environment that would meet the needs and capabilities of each child regardless of the characteristics of their psychophysical development" [6].

Inclusion implies that children with disabilities receive more opportunities, both socially and in terms of learning. This type of education contributes to a comfortable atmosphere for the child, in which his abilities and needs are taken into account and assessed adequately, as well as where the child would feel accepted.

We can also note the goal of inclusive education which is the creation of a coherent, effectively operating system of inclusive education for handicapped children and children with disabilities. In other words, the goal is the creation of a society that will allow all children and adults, regardless of gender, ethnicity, capabilities, presence or absence of developmental disorders to fully participate in the life of society and make their own contribution [11].

Inclusive education is based on the acts of international ("UN Convention" Art. 26.1.2) and state significance ("The rights of the child" Art. 23, "On the stand against discrimination in education" Art. 24, "On the rights of people with disabilities" Art. 24, "Social protection of disabled people No. 181 of the Federal Law").

To implement the educational process and social adaptation of a particular child in full accordance with his special educational needs and capabilities, an integral system of special educational conditions specified and implemented in work programs is required (Government program "Social support of citizens in the Vologda oblast for 2014-2018").

Experts note the following advantages of inclusion for children with disabilities: all children have equal access to education; children with disabilities demonstrate a higher level of social interaction with their healthy peers in an inclusive environment compared to children in special schools. This becomes especially obvious if the teaching staff at school purposefully support socialization, and if the number of children with disabilities is in natural proportion in relation to the rest of the students on the whole [9].

In an inclusive environment the social competence and communication skills of children with disabilities are improved. This is largely due to the fact that children with disabilities have more opportunities for social interaction with their healthy peers, who act as the carriers of the model of social and communicative competencies that is common for this age.

In inclusive classrooms, friendship between children with disabilities and healthy children becomes more common. 
. This is especially evident in cases where children with disabilities attend school near their place of residence and therefore have more opportunities to meet their classmates outside the school. Teachers play a crucial role in establishing and strengthening such friendships [4].

However, for the Russian education system inclusive education is a pedagogical innovation that is at the stage of implementation, and therefore is accompanied by certain difficulties.

The problem of the unpreparedness of general school teachers to work with children with special educational needs arises straght at the first stages of the development of inclusive education, the lack of professional competencies of teachers to work in an inclusive environment and the presence of psychological barriers and professional stereotypes of teachers is revealed [12].

The modern world is not yet fully ready to accept people with disabilities, this implies in particular to the emotional factor of society. For most Russian people, seeing a person with disabilities is like meeting a leper, they feel fear. Perhaps this is due to the fact that with regard to the situation of publicity, a person rarely meets people with disabilities. People feel uncomfortable and do not know how to set up communication, they do not realize that these are people just like them. Since people tend to exaggerate, they turn to be suspicious of anything and try to find confirmation that people with disabilities can be dangerous.

Universities mostly prepare graduates for teaching in general education schools, rather than specialized ones, therefore there is a need for comprehensive assistance from specialists in the field of correctional pedagogy and special and educational psychology later, at the stage of working activity. Assistance is required for the comprehension and implementation of approaches to the individualization of teaching children with special educational needs [1].

It is also worth noting that at the present moment, it does not seem possible to guarantee inclusive education as an expensive project which should provide the creation of a certified special educational environment in general schools together with preservation of the existing system of special education, improvement of its material conditions due to a certain unloading (reduction in the number of students per teacher) are impossible.

Nazarova N.M. notes that "in addition, domestic educational integration is being introduced today without serious special training of a teacher and a psychologist of the mass education system to work in conditions of integration. Pedagogical universities and pedagogical colleges today do not possess the technologies of preparing for work in the conditions of inclusive education neither for teachers of general education schools, nor for special teachers of various specialties" [8].

There are certain directions, forms and methods of working with such children. The main thing is psychological and pedagogical assistance, which clarifies diagnostic and corrective directions. Informative and organizational work is also necessary, both with children and with their parents, because the child-school-parent relationship is the best way to help children in view of their correctional work to reach the level of their grade. In addition, such activity solves one of the main problems which is the lack of communication $[5]$.

The effectiveness of a pedagogical worker when working with children with special educational needs is measured by the psychological readiness to emotionally accept such a child or children.

However, according to psychologists as N.M. Pershina notes, "emotional acceptance in pedagogical activity has a professional "barrier". The teacher does not psychologically accept a child, whose learning success is yet to be found out. The teacher does not know how to evaluate their individual achievements, how to test their knowledge. Concerning 
children with sensory impairments there is also a communicative barrier, "misunderstanding". The most problematic group is children with intellectual disabilities. They are obviously not able to master the curriculum of a general education school, most often they need a special structure of an individual educational route and use of a different educational program, which is extremely difficult for a teacher of a general education school (even if the school is licensed for several types of educational programs) " [10].

According to statistics, the success of the teacher's activity can be noted relying on their sufficient degree of personal and professional flexibility, endurance, readiness to solve emerging problems and a positive attitude towards themselves and the results of their own activities. The effectiveness of work in these classes is combined with sufficient preparation of the teacher for each lesson as well as the analysis of cognitive, communicative, behavioral characteristics under consideration, the individual style of assimilation of the material of each student in the class, including the "special" child [14].

It is not so difficult to work with such children if one knows and is able to apply all their experience and pedagogical skills, as well as rely on the following methods of inclusion: it is easier for a child to work through play as well as through any other activity. It is known that in spite of their lack of development of the volitional sphere children are more actively striving to work if it takes place in a group, where it is necessary to unite with the same students as they are. All types of activity should not be very different from what healthy children do so that children with disabilities do not feel alienated. And the most important thing is to accept students with disabilities "like any other children in the class" [2].

The experiment was carried out on junior schoolchildren of Type 7.2 of adapted education program with prolonged periods of study on the basis of Secondary School №9 in Vologda.

To identify the subjective opinion of specialists in the issue of correctional and inclusive education in schools in the city of Vologda and the Vologda oblast a survey was conducted. Teachers of the city and the region aged from 22 to 54 years old took part in the questionnaire. The teaching experience of the respondents varies from 1 to 31 years.

This survey was conducted with the aim of identifying schools with inclusive and remedial education. The results are as follows: inclusive and correctional education is included in educational activities in $65 \%$ of schools in the city and region at the moment. In this regard, it is possible to conclude that there are more opportunities for socialization of children with disabilities.

Next, we will consider the answers of the respondents who answered positively to the previous question, as well as in the subsequent questions we will analyze the answers of teachers who are not faced with inclusive and special education. Not all interviewees work with inclusive and remedial classes concerning schools where such education is available. Namely $25 \%$ answered negatively, $25 \%$ teach one inclusive or correctional class, $15 \%$ teach both an inclusive and correctional class.

Let us analyze the answers of all respondents to the open question "Do you think schools have inclusive and special education?" The respondents have the following opinions: $45 \%$ recommend this education for children; $10 \%$ lean towards a positive answer; $10 \%$ find it difficult to answer; $15 \%$ completely deny the need for this education; $20 \%$ did not answer. Based on these results, we can conclude that the teachers of the city and the region are positive about the introduction of inclusive education in general education schools.

The purpose of the next question was to find out the attitude of the respondents to disabled children. $30 \%$ of the respondents respect them; $45 \%$ do not highlight their limited health capabilities; $20 \%$ are neutral; $5 \%$ feel pity. After analyzing the results of this question, we noted that the overwhelming majority adhere to one of the principles of inclusive education which is not to focus on developmental peculiarities, but to accept 
children with all their educational needs. As for the question concerning special education in the field of physical education, only $5 \%$ of the respondents answered positively.

As the next question the psychological technique of projecting the situation onto ourselves was used, namely "You noticed that teacher X from school \# 0 in every possible way emphasizes the student's disabilities and makes fun of them in front of the class. What would you do?" The overwhelming majority are inclined to answer "I would reprimand the teacher."

Determining the level of teachers' adherence to special adapted education programs for children in inclusive and correctional classes we found that $5 \%$ of respondents take readymade programs, $15 \%$ make up programs themselves, $80 \%$ do not work according to the program.

Therefore, we can conclude that the problem of our research is really relevant, since there is a lack of work programs for correctional education in general education schools, as well as there is no sufficient competence of teachers to develop their own methodology.

In the answers to the open question "In your opinion, what does inclusive and remedial education means for the school?" we noted the following opinions: the majority is inclined towards full-fledged education and a tolerant attitude $(55 \%) ; 15 \%$ of respondents are in favor of partial education; $15 \%$ consider it extra work; $15 \%$ did not answer the question.

On the issue of the difference between adapted programs and general education programs $80 \%$ of respondents believe that there are differences, while noting individual health characteristics.

To determine the physical fitness of the tested we made a decision to use the method of sensory and motor tests, and based on the results and having compared them to the age norm we tried to develop a program to achieve the indicators of physical development of the general education class. In testing we used the following tests: jumping rope for 30 seconds, bending down from a standing position, balance in the pose of arabesque with eyes open, long jump from a standing position, throwing a $1 \mathrm{~kg}$ medicine ball from a sitting position, pulling up from a prone position, shuttle running $3 \times 10$.

In the 30 second jumping rope test the results of the control group are statistically significantly higher than the results of the experimental group, namely by $35 \%$.

In the bending down from a standing position test the results of the control group are statistically significantly higher than the results of the experimental group, namely by $54 \%$.

In the balance in the pose of arabesque with eyes open test the results of the control group are statistically significantly higher than the results of the experimental group, namely by $33 \%$.

In the long jump test, the results of the control group are statistically significantly higher than the results of the experimental group, namely by $10 \%$.

In the test on throwing a $1 \mathrm{~kg}$ medicine ball from a sitting position the results of the control group are statistically significantly higher than the results of the experimental group, namely by $7 \%$.

In the test on pulling up from a lying position the results of the control group are statistically significantly higher than the results of the experimental group, namely by $56 \%$.

In the $3 \times 10$ shuttle run test the results of the control group are statistically significantly higher than the results of the experimental group, namely by $26 \%$.

Thus, it can be noted that the results of children from the experimental group are significantly lower than the results of children from the control group, especially dramatically the experimental group lags behind in terms of the development of flexibility, strength endurance and speed-strength abilities.

Analyzing the modern development of special education, we came to the conclusion that we need new means and methods of teaching children with special educational needs, in this regard we have developed an adapted work program for the development of physical 
abilities of children with disabilities, so that they do not lag behind from their peers in terms of physical development. The result of correctional work should strive to transfer children from the class of developmental education to the general education class.

The adapted work program developed by us was worked out in a class with children of Type 7.2 of secondary schools on the basis of the Federal State Educational Standard of the primary general education for children with disabilities.

Teaching children with disabilities in Grade 1 is carried out for 2 years. During the experiment theoretical and practical lessons, pedagogical and medical supervision, as well as sessions with a psychologist were held. All of the foregoing helped the children to adapt to school education and reach the grade level.

As the peculiarity of the methodology we can note the presence of extended rest intervals with the inclusion of relaxation exercises both in the gym and sensory room, the use of brighter symbols as well as an increase in their usage during the lessons. All exercises were based on an associative series of objects and phenomena studied before, since it is known that children with intellectual disabilities (ID) have a low level of cognitive activity and limited fragmentary knowledge and ideas about the world around them.

The development of cognitive activity of junior schoolchildren with intellectual disabilities is understood as a process of correctional and developmental education including the correction of behavior and emotional-personal sphere of children with intellectual disabilities as well as overcoming the education drawbacks in the study of various disciplines, namely Russian, Reading, Environmental Studies.

After analyzing numerous data as well as studying the pedagogical experience we noted that the cognitive activity of children with intellectual disabilities amounts to the confirmation of the necessity to use individual games, the selection of which is random, the content is not scientifically substantiated and the effectiveness has not been proven, which significantly reduces the effectiveness of correctional and developmental work. Therefore, we selected methods and means for work on all of the identified types of correctional work with particular attention, taking into account the peculiarities and capabilities of children with intellectual disabilities.

Due to the fact that the emotional-volitional sphere of children with intellectual disabilities is impaired we decided to add the use of various relaxation exercises during the lesson. This helps not only children with disabilities but also healthy children because a child's body that is not used to heavy training weights can recover and move on to new exercises much faster, and school causes certain stress on a child. Besides mastering relaxation exercises makes it possible to do them at home by oneself, which gives a child more energy to do homework without overexerting their body.

In our opinion, carrying out such exercises through play will help to teach the child how to relax correctly in various situations, whether it is stress relief or concentration. Most of the tasks are based on an image that entertains children. When performing such exercises in addition to the main function of relaxation children embody the analyzed image and not just imitate the game's odd man out. For most children it is not difficult to understand the right way of performing these exercises, so the effectiveness of the tasks can be seen only by looking at the child. At the same time, breathing calms down and becomes smoother, the child stops breathing through the mouth, the face expresses calmness, there is no redness and the muscles that look slightly sluggish are relaxed. Due to the predominance of inhibition over arousal some children experience drowsiness and signs of yawning. The purpose of such tasks is to balance behavior, calm the child and experience shows that children sleep better.

Currently inclusive education is helping children with disabilities to learn to accept their own physical self, which reduces feelings of inferiority. Consequently, the main identified 
psychological problems in communication such as fears and phobias decrease, which has a positive effect on children.

At the lessons a variety of tasks were completed which decreased in time to complete and increased in number thus helping to keep the attention of children with special educational needs throughout the lesson without hampering physical activity. A clearer explanation of the material was achieved through shortened verbal instructions as well as more frequent and larger repetitions. Clear boundaries and lesson stages typicality helped the children to orient at the lesson better since they already knew the order of the lesson stages.

Encouraging the efforts of the student with disabilities was increasing. Reflection and discussion always ended on a positive note and there was no focus on the child's differences.

Group work prevailed among more quick-witted learners as well. The classes were strictly regulated by theme and lesson planning. Due to the fact that the experiment was conducted on the basis of a general education school the general sections in the field of physical education were taken as a basis, and we began to develop our own adapted program specifically for Type 7.2 children building upon the main general education program.

Types of corrective work carried out are the following: development of the accuracy of perception based on movement coordination exercises; correction of memory processes based on memorization exercises; correction of cognitive activity based on physical activity; development of communication skills; correction of spatial relationships based on movements coordination exercises; correction of attention based on comparison and discrimination exercises; correction of the emotional-volitional sphere of those involved in the exercises; correction of vestibular stability based on balance exercises; correction of spatio-temporal relationships based on training exercises.

In all sections of the educational program in addition to basic education, we introduced exercises making it easier for children to navigate in the subject called "Physical Education" in the first and first additional year of study. At the same time we made the children understand that they should not rush when completing assignments. Therefore, they began learning by the simplest tasks that are unconsciously completed by children in their lives, then the tasks were gradually complicated. From simple to complex is one of the principles of physical education, so we tried to adhere to this using a large number of preparatory exercises and dividing each element. Children did not know that they were performing facilitated actions, thus we emphasized the importance of completing general education tasks.

So in the "Athletics" block we used the basics of jumping tasks to teach the high jump starting from the easiest jumps and moving to difficult jumps for a given age in terms of coordination. By means of school equipment we installed the racks with a stretched elastic band imitating the bar a little lower so that children could perform many other actions in addition to the main high jump: stepping on the elastic band with the right or left foot; stepping over the elastic band with a high rise of the thigh with the resistance of the elastic band; front, side or backside jumping on one leg; front, side or backside jumping on two legs with different heights; pulling the knees to the chest; doing a gymnastic bridge. We also asked children to do climbing and crawling under a stretched elastic band both on mats and gymnastic benches.

For the development of speed abilities ordinary jumps were combined into complexes: jumps on one leg; jumps on two legs; jumps on two legs forward and backward; left-right jumps complicated by jumping strictly on the count); jumps with forward movement on one or two legs; jumps with turns to the right or left on one or two legs; jumps with legs together and legs apart (with the complication to jump onto a small height - disc ); jumps 
with a change of legs; jumps with a step onto a bench and further jumping up; skater jumps; jumps from low heights; jumps on a soft obstacle, etc. The jumps were complicated by adding hand movements: claps; simultaneous and alternating rotation in the joints of the upper shoulder girdle. First long jumps were performed from a half-squat position, then hand movements were added.

To teach children how to run, the exercises for teaching a high start were taken as a basis: start with a "fall"; hand resistance to simulate leg extension; a high start from various starting positions.

To practice a high start as well as to prepare for the control standard we used a shuttle run. The constant change in distances, the way of touching the control point and changing the direction of movement by audio and visual signals allowed children to develop space coordination.

We also used the simplest tasks with barriers and a coordination ladder. To develop the muscles of the back, we added a resistance band, fixed to the wall bars, which created resistance when jumping over the barrier into a specific cell of the coordination ladder.

Throwing balls helped us develop the shoulder girdle muscles. To begin training, we used light balls so that there was no heavy load on the weakened body. Before the first passing of the standards, we already gave the children a try of throwing a 1 kilogram medicine ball. There was a target to throw at, throwing at a distance, with one or two hands, in a limited space of a given corridor and through an obstacle were performed.

Learning the technique of passing the obstacle course time-trial alongside with an organized tourism week gave the children an expanded knowledge of nature and the elementary rules for camping. We conducted a lesson titled: "We are going on a hike together" with the subsequent development of a project on the topic "Overcoming the obstacle course" timed to coincide with the theme-week at school. The obstacle course has been created with clear boundaries and station markers to prevent children from getting confused. All exercises were selected based on associations with nature and explained to children. During such a lesson, safety precautions were observed, the teacher monitored the correctness of the exercise technique.

At home the children drew a knapsack with all the equipment for the trip. All data was explained to the children during the lesson, and was also given in the form of printouts for clarity. The task was to compare the data.

In the "Gymnastics and elements of acrobatics" section we used generally accepted static and dynamic exercises.

Preparing the body of students for acrobatic tasks we began training with straddles and tucks. Preparing exercises were the following: standing forward bends; squats with the grip of the legs and hips from behind; lifting the knees to the chest while lying; tilting the body to the legs in the long sitting position with the legs together; legs flexion simultaneously with the body bending and the shin grab.

The exercise "arch" helped to consolidate the learned elements of acrobatics as well as to bring something new to the familiar exercises by means of a variety of additional elements used. Climbing was carried out on a gymnastic bench, fully securing the place of work with soft mats and constant teacher supervision. The height was adjusted to the position of the body. In addition to climbing, the children climbed over the obstacle.

We started the shoulder stand with the well-known roll back. When teaching somersaults, an inclined surface was used to facilitate rolling over the head and remove the fear of performing the movement.

The mentioned movements were used during acrobatic combinations. The children tried to come up with their own personal combinations. 
The first steps in learning balance beam exercises were taken with the use of a bench. By performing basic exercises both on a wide and on an upside down bench the students learned balance.

In the "Sports and health-improving activities" section we mainly used general developmental exercises using various equipment. Small sandbags are great for firstgraders as they are light and soft. Observing all safety rules including sewing the bags to avoid getting sand in the eyes we gave such tasks as bag passes, tilting with bags, holding bags on the head, lifting the bags. For motor-coordinating development we used balance exercises with bags. The use of bags in tossing helped us develop dexterity, influenced the development of fine motor skills.

Combination of the bags with tennis balls gave a variety of tactile sensations, besides hands did not get used to holding one particular thing. The tosses were both with the use of one hand and both. In addition to individual work there was also work in pairs and groups. The small weight and volume of this equipment helped the children to start making passes correctly from the very beginning, which subsequently affected the ball passes in sports and outdoor games.

Elementary juggling exercises created a favorable emotional background as the children associated themselves with circus performers, which demonstrated the level of their cognitive activity and gave a boost to create other exercises based on the associations.

By the time we have strengthened the arms and body muscles the children were doing the following medicine ball tasks: lifting balls with different arm movements and bends; passing balls in pairs, column and line, along the way renewing the position; throwing the ball over the net and taut belt; rolls of the ball around oneself, a partner, in a column and in a line from the front, from behind and alternating; juggling; passing balls with partial vision control. All this was aimed at correcting children's eyesight and developing the accuracy of perception based on coordination tasks.

For the body development and carrying out corrective work of cognitive activity based on physical activity we worked with various simple equipment such as a jump rope. For training we used preparing exercises: rotation of the rope folded in half on the right and on the left; the same exercise with the addition of jump on two legs; the same exercise but with a jump on one right or left leg; throwing the rope from behind and stepping over; throwing the rope behind the back and stepping over; the same exercise but with the addition of a single jump; the same exercise with the main jump and the addition of intermediate ones.

Exercise "Horse" in addition to learning to jump rope helped the children to work out a special running exercise in the future which is running with a high hip lift. Children began to perform significantly better, the amplitude of movement became higher.

Back extensions have a positive effect on the mobility of the hip joints and also serves as a prevention of flat feet because the task can be completed without shoes.

To correct memory processes, we used the "Wave" exercise. This exercise can be used as a control test of the knowledge of general developmental exercises, since children perform previously learned elements and they need not just to repeat them but remember them while performing another task.

In teaching we also used exercises with gymnastic sticks in order to facilitate more accurate fixation of the position of the arms, body, head and legs. Specifying the value of these exercises we can note that with the use of gymnastic sticks it is easier for the teacher to control various positions. When the gymnastic sticks were used while walking, we also reminded the children of boundaries and control points while rearranging.

Exercise "Stork and Frog" is aimed at developing coordination, attention and memorization. When the number of signals had increased to two, the children were already more attentive to the task. 
To develop spatio-temporal relationships based on training exercises we used the "Feel the time" task. Fixed parts from the relaxing exercise "A Minute" familiar to children were given them to cover a defined distance which changed as well as time did. This exercise in addition to being used in the gym was given and revised on a landing and in ski training lessons.

The children's basis of knowledge about a healthy lifestyle was formed in kindergarten, so we reinforced the children's conceptual framework by conducting a quest game "Me and a healthy lifestyle". At the lesson the children determined the importance of a healthy lifestyle based on the knowledge gained earlier. The content of the lesson included a theoretical foundation of a healthy lifestyle, a practical test with choosing the correct answers (matching the pictures to the correct column), checking homework (making up your own morning gymnastics complex). As a continuation of the practical lesson, a theoretical lesson was held with a cartoon and drawing on the topic "What is a healthy lifestyle". After these lessons students reflected on what they knew, agreed that there was a lot new for them and it was worth maintaining such a way and standard of living.

In the "Outdoor games" section we tried to vary the simplest games. For example, when playing "Owl" the children were asked to depict certain animals after studying them at theoretical classes as well as at other lessons, which can be considered an integration and interconnection between other educational process subjects such as Russian, Literature and Environmental Studies.

The exercise "What has changed" is excellent for correction of the memory processes based on memorization exercises. Children should notice the rearrangement, absence or addition of one or another item in the variety of objects. Communicating with each other children not only learn about society but also develop communicative skills. Various competitive activities and games are aimed at ensuring that children learn to find contact with peers in their class. The "Question-answer" task was given in the second grade, because it made the task of motor actions fulfillment more complicated by means of questions to which it was necessary to answer simultaneously with the tasks performance, that is without stopping.

The task "Guess what I thought" was given to students so that they have a figurative idea of the object, since associative thinking of children with intellectual disabilities is developed poorly. In addition, the children could guess objects themselves by describing them. Thus, we could trace the success of our classes.

Knowing that children with special educational needs do not have fully developed concepts of top, bottom, right and left, we used the task "What's on top, what's below?" in order for children to remember the possible location of some objects by simple common examples.

The children played the "Teremok" game with a great interest. Two other games, namely "Cosmonauts" and "Molecules" were combined in it, both of them are well-known among children. This game had a double role: it helped to gain spatial awareness and also developed the children's attention.

Relay race tasks had a great impact and were performed most of the time. "Cooking borscht and compote" is a simple task for children on the knowledge of household food. It was performed both by the whole class and by two teams. The task was to cook their "lunch" correctly. When there was a mistake, then together with the child we figured out where exactly the chosen "ingredient" had to be put.

The "Take My Place" exercise continued to teach column formation and area location. Due to the fact that the task was performed with a change, so the children did not get used to doing the same thing but tried to think in the right direction.

In the "Sports games" section, namely basketball, volleyball and futsal we made up tasks mainly for catching and passing the ball, since more complex elements are difficult 
for children with special educational needs at this stage of training. The basis for learning the technical elements was achieved by various passing and throwing of the ball.

The game "The ball to the catcher" helped to understand how to act in a team. At first children could not throw the ball up with one hand, but with the subsequent work on the development of the shoulder girdle muscles and the development of dexterity by the end of the first grade the children were able to play the more complicated version of this game in terms of motor coordination.

We taught stands for these sports by means of exercises on attention. When performing general development exercises with balls a signal was given in order for the children to take the necessary position. The connection between specific signals and stands was previously explained.

In the first additional grade the simplest exercises for juggling balls with one as well as two hands were added. These exercises caused children's emotional outburst and a desire to achieve their goals.

The "Little Octopus" game united the class perfectly despite the division into teams. In the course of one lesson children could switch teams several times, and this did not prevent them from fulfilling their task which was to score the goal to the gate.

In the "Ski training" section, our task was to introduce the simplest rules for handling ski equipment and types of formation and change of formation. Safety training was conducted without skis. It started with preparatory exercises. First of all, we used balance exercises, since the snow cover is different from the solid floor at the gym and the children needed to get used to the change of the environment. In addition, training is carried out without ski sticks, therefore, it was necessary to develop children's coordination in space so that children do not fall over when they cover distances. The preparatory exercises were first carried out in the gym on an upside down bench, then these exercises were performed on the street without skis, and when confidence in their abilities appeared the children put on the skis and tried to complete the tasks, first without moving and then in motion. It was important to teach the correct transfer of the center of gravity from one foot to another. To achieve this, the children were asked to perform squats on one leg, the "skate" stance and the "classic" stance. On a slight slope the children skied on one ski. They were also given tasks on jumping up.

The children carried out the change of formation from lines to columns and vice versa the same way as at the gym according to the given reference points. We also asked the children to cover distances without ski track on both deep and shallow snow in addition to the distances on the ski track.

The beginning of the training was based on teaching children to perform ski stepping. Next we had to teach ski sliding and the turn by stepping over both the tail of the skis and the nose of the skis. The "Scooter" exercise is perfect for teaching ski sliding. The purpose of the exercise was to put the foot with the ski on the track and push off with the second foot without the ski on.

The exercise "Collect along the way" was used for continuous sliding without pushing off with sticks. Flags which had to be collected simultaneously with the push from them were located at a distance of 10 meters.

The exercise "Make it to sit down" was used so that the children were more attentive to the reference points located on the limited area or the ski track. Driving past the bright reference points the children skied squatting while maintaining slide and balance.

The "Physical culture and recreation activities" section is aimed at ensuring that children learn the correct ways of formation and reformation. The beginning of the formation training was carried out by holding hands with the teacher. Then, so that the children did not get confused the formation was kept in the same marked place. The marks 
were made with masking tape. After a while in order to develop attention we asked the children to form on signal having previously discussed them.

Besides the reformations we used various types of walking, namely crouch walk on toes, walks with different hands positions, alternation of standard walking and walking with different hands positions on the count, walking with claps, walking accompanied by chants, slowdown and accelerated walking. All turns were performed according to the reference points. At the same time children found out why they need a warm-up. By the second year of study the students had some physical activity experience, so they were asked to conduct general developmental exercises by themselves.

For the exercises the children were given flags, therefore, the routine conduct of the preparatory part was diversified. The advantage of adding flags is that children focus on the correct execution of the elements as it is necessary to maintain balance.

In addition to the flags we constantly tried to diversify the exercises using a gymnastic bench or wall bars. The presence of support for children at the initial stage of training had a positive effect on the quality of the performed movements.

In this section the children were not only given prepared gymnastics exercise complexes on eyes, hands (mainly for prevention of hand injuries) and posture, but also were taught to make up their own complexes. Also when the children were at school, they independently organized themselves for exercise breaks which they developed and learned at the lesson in advance.

Getting familiar with balls which are the main equipment was carried out within the project "Ball Games". At the lesson the children got acquainted with and examined various types of balls. The task for the children was to correctly determine the sport of this or that ball and to perform specific actions with it. Besides the children were asked to lift each ball in their hands and then put it down.

Finally, the exercise "Find a match" was conducted, the purpose of which was to find out how well the children learned the material. The children were looking for a pair to the given balls. In addition to their choice explanation, they also got to know tactile feel of the balls determining its weight, shape and purpose.

The homework was to make a creative painting representing the children's knowledge on balls, which is not provided by the educational organization. The children could do their homework together with their parents, which was considered as correction of communication skills.

In the "Theoretical Knowledge" section we told the children about safety at the gym and outdoors by means of a presentation. Besides the children acquired knowledge visually when they watched cartoons on sports topics. They also tried to answer questions after watching. At the theoretical lessons the students got acquainted with the additional equipment and studied the necessary information.

We talked about famous athletes, discussed the body structures so that it was easier for the children to remember what to warm up and how in order to prevent injury. The result of this work was an optional warm-up at the beginning of the lesson conducted by the children themselves. The children had some thoughts about what to do in advance which were based on the topic of the lesson. For example, when there were athletics lessons the children paid more attention to leg stretches and lower extremity muscles warmup.

At the theoretical ski lessons we told about the methods of skiing, rules of conduct, clothing selection and injury prevention.

Apart from that classes in the sensory room can be noted. It is a specially equipped room which is designed to affect all the senses and achieve various goals, namely relaxation, activation and development of the senses.

The sensory room exercises overlap relaxation exercises due to the fact that children with special educational needs are much more fatigue. There was a dry pool which was 
used for a light massage with balls. We tried to ensure that the children were calm by drawing various figures in the air with our hands and feet.

In addition to the massage function, the "Swimmer" exercise gave the basics of theoretical knowledge about swimming provided by the program. The "Bubbles" exercise had a beneficial effect on the breathing of children. Along with this, since there is "a place to swim" then there must be "a beach". It was the exercise of the same name that we used for psychomotor regulation, which was accompanied by a visual picture and calm sounds in the background.

More active tasks were conducted with the use of soft objects and observation of the bubble tube. The task was to repeat the bubbles movements or climb onto the objects. The children performed the exercises "In the rain" and "Catch the rain" to the sound of rain using fiber optic cables. Exercise "In order" is aimed at the sense of touch development and helps to get used to the new equipment.

All exercises in the adapted work program developed by us alternated with relaxation exercises. Thus, the children did not feel fatigue during the lesson and correction of the emotional-volitional sphere was conducted.

The "One Minute" exercise helped to restore the breathing and heart rate of children. Since the children were initially limited in their ability to count, we simplified the game up to 10,15 and 30 seconds. At the very beginning the children watched the stopwatch, thereby memorizing both the numbers and the flow of time.

Gentle names for relaxation exercises have a positive effect on cognitive inhibition processes. For example we used such tasks as "Little Cloud", "Sleeping Kitten".

Respiration was restored when performing breathing exercises, namely "Ant", "Tree", "Five candles". The exercise "Guests" must be noted which in addition to its main function influenced the speech apparatus, due to the fact that it was necessary to recite poems, while performing language gymnastics.

To relieve emotional stress, we came up with a task called "Shake It Off". The children were asked to imagine how they were brushing off all fatigue and tension. The second exercise "Kolobok", which children know after the study of the acrobatics section as the somersaults preparatory exercise, was already used with the words "I escaped from grandma, I escaped from grandpa" from the fairy tale of the same name. The "Cold and hot" exercise was used both without walking and in motion depending on the type and amount of physical activity at the lesson.

Thus, by following this program it is possible to achieve visible results of a student's activity, since the great work that has been done with the use of the abovementioned exercises and games helped to enable children with intellectual disabilities to keep up with their peers.

At the end of our experiment, we retested the trainees and the results of the test make it possible to trace the increase in the performance indicators of the control group, as well as the increase and alignment of the performance indicators of the experimental group with the age group.

According to the 30 second jumping rope retest the result of the experimental group was $6 \%$ higher than the results of the control group. In the bending down from a standing position retest the result of the experimental group also became $2.5 \%$ higher than that of the control group. In the balance in the pose of arabesque with eyes open retest the result of the experimental group became $3.2 \%$ higher. In the long jump retest the result of the experimental group exceeded the indicators of the control group by $1.1 \%$. In the retest on throwing a $1 \mathrm{~kg}$ medicine ball from a sitting position, the result of the experimental group exceeded the indicators of the control group by $5.1 \%$. In the retest on pulling up from a lying position the result of the experimental group exceeded the indicators of the control group by $8.4 \%$. In the $3 \times 10$ shuttle run retest the result of the experimental group leveled 
off with the indicators of the control group. In the course of the study, it was revealed that the developed adapted work program used by us brought the results of performance indicators of children with disabilities closer to the results of the age norm of the general education class. We determined empirically that due to the special educational needs of children, they needed more "expanded" means of physical exercises. A great number of preparatory exercises for certain elements of physical training, as well as general development exercises with balls, jumping ropes, a gymnastic bench and wall bars as well as without any equipment created a kind of "safety cushion" of knowledge and skills in the field of physical education for the children, which will help them not to get confused when performing more complex tasks provided by the program at future lessons.

When studying the theoretical basis, we highlight the fact that it is important not to overload children, give them repetitive information for better reinforcement, as well as that completing tasks with children gave an impetus for the development of several important factors such as increasing children's self-esteem, creating a friendly atmosphere and the emotional background of the lesson. The exercises on relaxation which we have correctly included into the educational process are innovative activities. At the same time, selfregulation of children's rest became a positive feature, since they learned a great number of exercises, which help not to get tired much and, if possible, avoid stress.

Competently selected types of correctional work with children with disabilities helped to form the program of our activities so that children did not experience great difficulties in understanding the subject "Physical Education".

The work we have done, from collecting information from literary sources up to drawing up conclusions, may indicate that the experiment was carried out successfully.

All didactic material was gathered considering intellectual disabilities, as well as concomitant diseases. Basically, these were speech disorders. Collaborative work with the class teacher, physician and psychologist helped to align the general level of knowledge, skills and abilities.

Bright and visual teaching aids had a positive effect on the emotional-volitional sphere of each child, and also helped not to get confused when completing assignments. All this had a great effect on the child's intellectual work, which was also noted at other lessons.

Thus, after the experiment we carried out we revealed an increase in performance indicators by means of the final motor testing. A noticeable lag behind the age norms of physical qualities decreased and children with disabilities became equal to their peers, therefore the adapted work program developed by us turned out to be effective and it can be recommended to specialists working with such children. Besides individual exercises from the adapted program can be used in inclusion classes for a differentiated approach to children with special educational needs.

In the future, it is necessary to continue the development of adapted physical education programs for children with disabilities of other age groups to increase the level of physical and mental performance and reduce the differences between children with any form of health disability from healthy peers.

\section{References}

1. Dadasheva, Z.G., Inclusive education as an innovation in the Russian educational system / ZG Dadasheva // Modern education: theory and practice: a collective monograph. - Ufa: AETERNA, 2017 .-- S. 114-117.

2. Dyssegaard, C.B., Larsen M.S. Evidence of inclusion [Text] / C.B. Dyssegaard, M.S. Larsen. - Copenhagen: Danish clearinghouse for educational research, 2013. - 55p. 
3. Federal Law of the Russian Federation «On Education in the Russian Federation» No. 273-FZ. - Moscow: Omega - L., 2014 .-- 134 p.

4. Fetalieva, LP Advantages and disadvantages of inclusive education and integration // Bulletin of the University. - 2015. - No. 8. - S. 312-315.

5. Giangrego, M., Doyle, M. B. Integrazion scolastica in Italy: A Compilation of EnglishLanguage Resources [Text] // International journal of whole schooling. 2012. Vol. 8 (1). P. 63-105.

6. Kolupaeva, AA Fundamentals of inclusive education: study guide. allowance / A. A. Kolupaeva, A. M. Taranchenko, I. A. Belozerskaya and others / ed. A. A. Kolupaeva. Kiev: A.S.K, 2012 .-- 307 p

7. Korobkina, I.I. Influence of mental retardation on school performance in children. [Electronic resource] // Medical psychology in Russia: electronic scientific publication. 2010. N 4. URL: http://medpsy.ru. - 2018.

8. Nazarova, NM Integrated (inclusive) education: genesis and implementation problems // Bulletin of the Moscow Pedagogical University. - 2009. - No. 3. - S. 8-18.

9. Nevin, A.I., Thousand, J.S., Villa, R.A. Collaborative teaching for teacher educators: What does the research say? [Text] // Teaching and teacher education. 2009. №25. P.569-574.

10. Pershina, N.M. Features of the teacher's professional activity in inclusive education / V International student electronic scientific conference «Student scientific forum». - 2013 --- S. 5.

11. Petriwskyj, A. Diversity and inclusion in the early years [Text] // International Journal of Inclusive Education. -2009. -Vol.14.- №2. - p. 195-212.

12. Pevzner, M. N. Educator in the world of diversity: leading ideas and expected results of a new international project / Inclusive education: problems and prospects: collection of scientific papers based on the materials of the international scientific and practical conference «Networking of universities with social partners in the field of inclusive education : international and regional aspect»/ comp. E.V. Ivanov; NovSU them. Yaroslav the Wise May 19-21, 2014 - pp. 24-34.

13. Qi, H., Rabren, K. An examination of co-teaching: Perspectives and efficacy indicators [Text] // Remedial and Special Education. 2009. Vol. 30(5). P.259-268.

14. Samsonova, E.V. Basic pedagogical technologies of inclusive education / E. V. Samsonova, T. P. Dmitrieva, T.Yu. Khotyleva. - Moscow: Pedagogical University: «September 1st». - $2013 .--36$ p.

15. Shamarina, E.V. Teaching children with mental retardation: the organization of individual and group lessons in the class of correctional and developmental education. A manual for primary school teachers and psychologists of classes of correctional and educational development / E.V. Shamarina - Moscow: publishing house GNOM and D. (series «Teaching children with mental retardation»), 2007. - $80 \mathrm{p}$.

16. Starostina, A.V., Starostina, Yu.M. The role of adaptive physical culture in sanatorium treatment of disabled children / A.V. Starostin, Yu.M. Starostina // Traditions and innovations of physical education of student educational organizations: collection of scientific articles of the All-Russian full-time correspondence scientific and practical conference / Ministry of Science and Higher Education of the Russian Federation, Vologda State University. - Vologda: VoGU, 2020 .-- S. 27-31. 